\title{
La configuración del "lar" en la poesía de Rolando Cárdenas
}

\author{
The configuration of the "lar" in Rolando Cárdenas's poetry
}

Biviana H ERn Án dez

Universidad Austral de Chile. Valdivia, Chile

E-mail: urganda5@yahoo.es

\section{RESU MEN}

El presente artículo analiza la visión lárica del sujeto poético en poemas de En el invierno dela provincia, de Rolando Cárdenas, texto en queel autor destaca la originalidad y autenticidad de la forma de vida provinciana, dotándola de un sentido mítico producto de la trascendencia que supone el desarrollo de sus ritos y actividades más cotidianas. Ello, en contrastecon la postura del sujeto teillieriano, donde lo lárico se define por los sentimientos contradictorios que éste experimenta y que no puede conciliar toda vez que percibe por y en sí mismo la imposibilidad de pertenecer a un mundo original.

Palabras claves: Poesía lárica, mundo mítico, trascendencia, nostalgia, extrañamiento, tradición cultural.

\section{ABST RACT}

This article analyses the poetic subject's laric vision in poems from In theProvincesW inter, by Rolando Cardenas. In this text the author stresses the originality and authenticity of life in the province, bestowing upon it a mythical character produced by the transcendent nature of the most common daily activities. Contrary to Cardenas's laric vision is that of the poetic subject in J orgeTeillier's poetry, in which thelaric is defined by the contradictory emotions it cannot reconcile as it perceives in itself the impossibility of belonging to an original, uncontaminated world.

Keywords: Laric poetry, mythical world, transcendence, nostalgia, not-belonging, cultural tradition.

Recibido: 05-10-2007. Aceptado: 28-10-2007. 


\section{PRESENTACION}

A UTOR deseislibrosdepoesía', Rolando Cárdenas, poeta magallánico (1933-

1990), ha demostrado en ellos la adhesión a la estética del lar, por medio de la confirmación y defensa de la propia cultura, en una suerte de reivindicación de las costumbres del habitante magallánico y las labores y oficios cotidianos de los personajes típicos de su ciudad natal (el organillero, el ladrón de gallinas, el florista o el vendedor de banderas); preocupación que revela su interés por aquella tendencia que Jorge Teillier, refiriéndose a su propia poesía, definió como "la descripción del paisaje visto como un signo que esconde otra realidad" (1968: 14). Por otra parte, la búsqueda de sus raíces, la conciencia del desarraigo y la soledad, efectos que produce la conflictiva inserción del poeta en la urbe, tienen quever con "la historia de un personaje contada con un marco dereferencia que es siempre la aldea” (I bíd.). Así, el personaje que retorna al pueblo de la infancia en muchos de sus poemas experimenta la sensación de extrañamiento, de un ser que ha mudado de carácter, que ya no es el mismo, pero que al volver recupera, a través del recuerdo y del contacto real con las cosas y la gente, la fugacidad de aquel tiempo pretérito en que la casa materna, la familia reunida y los amigos eran para el sujeto las únicas y más fieles certezas de su existencia. En el presente, el habitante provinciano percibe la decadencia del mundo producto de la irreversibilidad del tiempo que todo lo consume, ve con angustia cómo todo es corroído por su paso, reaccionando con dolor frente a la ausencia de sus seres amados, pero con un optimismo vital, que lo incita a superar todo sentimiento de pérdida o vacío existencial, experimentando la seguridad en sí mismo, en cuanto afirma el contacto mítico con sus orígenes.

En la configuración de su mundo cultural se funden los motivos de la geografía del propio hábitat, los modos de vida del habitante magallánico, sus primeros hombres, la soledad, la tristeza, así como la conciencia de la inutilidad del sujeto frente al tiempo que transcurre. $Y$ si bien éste tiene la certeza de que lo único seguro es la muerte, hay un intento por retornar a la infancia y capturar el tiempo de la memoria ancestral, en cuanto confirmación de un sentido para la vida presente. Así, la voz que resuena en la casa de la niñez, las calles del barrio, los árboles, el mar y los objetos que aún resisten la historia y su temporalidad, confirman el deseo del sujeto por activar la memoria de un espacio-tiempo inmemorial, de manera tal que el esfuerzo consciente del poeta por trascender el tiempo, aunque sabe inútil, sólo encuentra asidero en ella toda vez que le imprime la confianza necesaria para resistir la caducidad de las cosas y seres amados por él.

\footnotetext{
${ }^{1}$ Tránsito breve (1959), En el invierno de la provincia (1963), Personajes de mi ciudad (1964), Poemas mi gratorios (1974), Q ué, tras esos muros (1986) y Vastos imperios (texto inédito).
} 
Se considerarán en este artículo dos poemas de Rolando Cárdenas: "La familia reunida" y "Regreso", correspondientes a su segundo libro de poesía, En el invierno dela provincia, con el propósito de analizar quéelementos temáticos de su poesía configuran una visión de mundo al decir lárico de Jorge Teillier. El análisis de estos poemas se hará en relación a la propuesta metatextual de este último -en sus artículos "Los poetas de los lares" y "Sobre el mundo donde verdaderamente habito"- respecto al significado y/o postura ideológica que le ha atribuido a la poesía lárica. Se recurrirá también a sus primeras publicaciones: Para ángeles y gorriones, El cielo cae con las hojas, El árbol de la memoria y otros, para determinar de qué manera la poesía de Cárdenas, en tanto visión de mundo, y deacuerdo con las propuestas tanto metatextuales como poéticas deTeillier, se inscribe dentro de la corriente lárica de la poesía chilena contemporánea.

\section{LO COTIDIANO AN CEST RAL Y FAM ILIAR}

En el poema "La familia reunida", de En el invierno dela provincia, el sujeto se muestra sensible a los gestos y objetos que acompañan a la familia de la provincia, en tanto constituyen los motivos que le permiten instalar su poesía en un ámbito trascendente. Los primeros cinco versos nos sitúan en una realidad ahistórica, en que la mesa, símbolo mítico de una forma de vida caritativa y solidaria, ha logrado superar el tiempo cronológico, fundamentando la vida en comunidad, auténtica y natural, que evoca el sujeto desde el presente para activar la memoria del hogar, y con ella, el espacio de lo cotidiano ancestral. Las costumbres de esta familia se hacen notar a través de la recuperación de sus actos rutinarios, los que son descritos de modo consecuente con el deseo del hablante por explicar cómo la rutina y la monotonía de los gestos son los el ementos que hacen posible la vivencia lárica, demostrando que lo que verdaderamente importa al poeta es testimoniar, cual observador y hasta cronista de la real idad que contempla, la experiencia de vida cotidiana de la familia magallánica; una forma de vida humilde que contiene la esencia de toda felicidad, esto es, la ternura y el regocijo de quienes son miembros de una alianza sagrada, de allí que los gestos cotidianos revelen las costumbres de la familia en su conformidad de vivir siempre de la misma manera:

Muchas veces rejuvenecían en secreto otros, tenían la madurez de la tierra, pero casi era una actitud invariable, un descanso, verlos otra vez de nuevo aunque la ternura era brumosamente igual y sólo la muerte los asombraba 
La casa y, sobremanera, la mesa conservan aquellos gestos que hacen de la vida familiar una vieja costumbre, en la que no existe temor ni angustia porque nada amenaza ni distorsiona su sentido original, cual es el de convocar a sus miembros en un pacto de unidad. La familia reunida, que no "teme a nada, ni espera demasiado", "como el día de ayer", confirma entonces que lo verdadero está en esas pequeñas cosas que da la natural eza, el hogar y sus gestos cotidianos.

En el invierno de la provincia está contenida la esencia de la materia poética de Rolando Cárdenas: su suelo natal, M agallanes. En éste se destaca con especial énfasis la geografía del paisaje austral, pero más, con exacerbada latencia, el deseo del poeta por hacer de la familia y el hogar categorías el evadas a la condición de mito. Ello explica que la mayoría de los poemas refieran las costumbres y formas de vida de sus habitantes. Así, en "La quinta de la casa" se observa este afán al aparecer la quinta como un espacio que ha trascendido el tiempo, y la imagen del abuelo como figura ancestral. D e esta quinta el hablante nos dice:
Al fondo de la casa está arrugada y dura
sin frutos ni perfectos molinos.
Pero las raíces tejen sus mansiones secretas todas las estaciones.
Es su ternura fecundada
como amadas lámparas bajo tierra

Y del abuelo:

Y mi abuelo -que junto a la tierra envejecíaera un antiguo vigilante de huertos y cosechas levantánd ose antes que el rocío con su pala y su cigarro a conversar con ella para guardarla de las grandes escarchas

Lo mismo ocurre en el poema "M anos tejedoras", en el que la imagen dela abuela aparece evocada simbólicamente:
La conocí curvada sobre su urdimbre todos los días como si encendiera el fuego
o dispusiera la mesa
mientras sus manos entretejían sin fatiga ventoleras de estrellas y vigilias

D el mismo modo, la preocupación por el espacio cotidiano familiar se material iza en la presencia histórico-mítica de sus primeros habitantes, los sel knam. En el poema "Fueguinos" se describen de acuerdo con el cariz de los anteriores: 
N unca supieron de la muerte

porque recobraban el tiempo en el secreto del agua

ahora son los ríos y los montes

las estrellas rojas que atraviesan la noche

También en "Antepasados" se alude a su presencia e influjo en las labores cotidianas, la comunidad y el entorno natural:

\author{
Muchos de ellos se fueron como ríos \\ hacia tierras donde ardían fogatas en la noche \\ M ás al sur llegaron con sus conjuros y sus braseros \\ a establecer la maravilla de sus sembrad os \\ y su harina tostada \\ sus sopas marineras y el pan moreno \\ Muchas manos más han aprendido de sus manos \\ alrededor de ellas como un círculo \\ y muchas más heredarán su agua y su greda
}

Los poemas de Jorge Teillier "El año que viene" (de Para ángeles y gorriones, 1956) y "Un año, otro año" (de El árbol de la memoria, 1961) tienen que ver con la temática del espacio cotidiano familiar presente en el poema deC árdenas "La familia reunida". Por una parte, en "Un año otro año" el sujeto confirma la monotonía de la vida mediante la certeza de que todos los días equivalen al mismo día, no habiendo para él novedad, ni siquiera asombro frente a un nuevo amanecer. Así, describe la rutina de los hombres que no esperan nada nuevo porque la vida se ha transformado en costumbre, al punto que las actividades diarias se ven condenadas a seguir funcionando en una línea de continuidad y mecanicidad, que le impulsa a perder todo estímulo frente al devenir del tiempo. En este contexto, el tono de impasibilidad queexhibeel hablantees producto de la misma monotonía que se hace parte de la vida de todo individuo:

Termina el trabajo. Y todos: miedosos avaros que al guna vez disparan contra las sombras del patio carpinteros ebrios, con las ropas aún llenas de virutas ferroviarios enhollinados, pescadores furtivos esperan en silencio la hora del sueño pronunciada por relojes invisibles

Al parecer, lo único que éste puede esperar es la hora del descanso al atardecer una vez terminadas sus labores cotidianas; el instante en que el sueño, por lo menos por unas horas, anula la conciencia del presente, eternamente igual. En 
estas condiciones, la atmósfera que se crea en el poema, in crescendo, revela un estatismo abismal: "N adie mira hacia las ventanas / nadie abre una puerta", otorgándole a la rutina un carácter de automatismo, según el cual los gestos y movimientos se hacen de manera inconsciente, en la medida en que no existen expectativas de cambio. D ada esta realidad, para el sujeto no existen situaciones inesperadas o distintas, es por esto que las actividades cotidianas no le presentan asombro como tampoco le impulsan reemplazarlas por otras nuevas. No obstante, su actitud anodina pareciera condecirse con el deseo de eludir esa suerte de mediocridad anclada en la rutina, que hace que las cosas pierdan su sentido. La misma situación es la que describe en el poema "El año que viene". En él, la inercia justifica las actividades cotidianas de los hombres, quienes no saben por qué ni para qué hacen lo que hacen, careciendo de principios o fundamentos que expliquen su diario vivir:

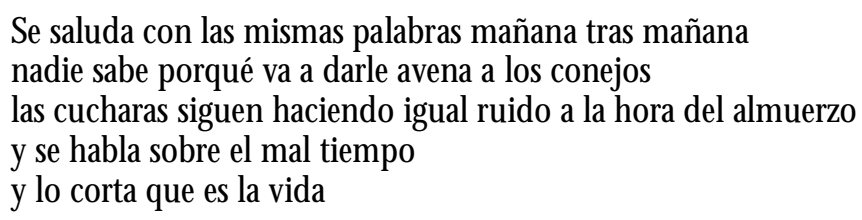

Y si bien Cárdenas describe en el poema "La familia reunida" la monotonía del rito de sentarse a comer a la mesa, éste no representa para el hablante la apatía que le provoca al sujeto teillieriano. Por el contrario, el relato que hace acerca de la manera en que convive la familia en el hogar, aun sin asombro y novedad, le sirve para confirmar su propia existencia como impregnada de fortaleza y sentido. La rutina no significa, en consecuencia, desarraigo 0 abandono, equivalea la confirmación del presente de acuerdo con la humildad y sencillez de los gestos cotidianos caseros, detenidos en el tiempo mediante el recuerdo del hablante. De allí que las escenas de la vida cotidiana que éste recupera puedan asociarse más a un tiempo considerado monótono que mítico, aunque en ocasiones ambos suelan coincidir.

N o obstante, la abulia que experimenta el sujeto teillieriano confirma que aun cuando la vida no sea más que la automatización de las labores cotidianas, ésta sí tiene en qué hallar asidero. Evidentemente que la rutina y la inercia que describe en los poemas "El año que viene" y "Un año, otro año" no sugieren esperanza ni confianza en al go distinto o mejor, más aún cuando su estadía en aquel tiempo eterno, el del mito, tampoco anula el tedio y el sinsentido de su presente. Confirman, sin embargo, que lo que existe en el mundo original dela provincia, lo que se presenta en él como realidad inmediata, le sirve para continuar viviendo dentro de esa rutina que, aunque desolada, es la única que puede 
brindarle pequeñas alegrías, "después de todo, ya se sabebien / que en cual quier parte la vida es demasiado cotidiana" (poema 17 de L os trenes de la noche y otros poemas, 1961). Esconveniente apreciar esa rutina - esa es la arenga del sujeto- y aceptarla como lo único cierto y verdadero de que dispone para existir, puesto que fuera de ella, al parecer, nada mejor puede ofrecerle el derrotero de la vida.

El poeta lárico experimenta la nostal gia por la infancia perdida, por esa Edad de 0 ro, en la que el tiempo se repetía inmemorialmente asegurando la plenitud de la existencia humana. $M$ as, en el presente ya no cuenta con esa confianza ni seguridad, puesto que, situado en un espacio y un tiempo que no le satifface, se halla extraviado en el mundo queletocó vivir por voluntad ajena, viendo reemplazada su auténtica vida de provincia por otra inauténtica y superficial, no arraigada en tradición cultural alguna, como es la ciudad moderna. En estas condiciones, no encuentra más remedio que sumirse en la nostalgia por el tiempo de antaño. D icha actitud es la que provoca cierto estatismo en la poesía de Teillier: el poeta se duele de existir en un mundo ajeno, que no le pertenece y que experimenta como alienado y antinatural. No obstante, las cosas que le permiten sobrevivir en él son aquellos objetos que conserva como verdaderos tesoros, reliquias o vestigios de ese otro mundo arcádico; objetos que aparecen en la modernidad impregnados de su historia y tradición cultural. Sin embargo, la contradicción termina apoderándose de él cuando descubre que su vida no adquiere sentido aun cuando logre integrarse al mundo del origen, aquel al que inexplicablemente retorna "como un desterrado para reencontrarse con algo que ya no existe" (N ómez, 1992: 327).

\section{RET ORICA DEL TIEM PO Y REGRESO A LA ALDEA NATAL}

Si bien para Teillier es posible el retorno a la aldea natal, éste se hace efectivo como experiencia de extrañamiento, debido a los cambios sufridos por el sujeto en otro lugar y a aquellos que naturalmente somete el paso del tiempo. Así, por ejemplo, el hablante del poema "Camino rural", que va hacia un pueblo donde nadie lo espera "porque a otro esperan allí", da cuenta de la enajenación que experimenta al volver: tanto más percibe que no es el mismo cuanto más confirma que su pueblo tampoco lo es. Esta conciencia de pérdida, quiebre o ruptura con la propia identidad es la quelo expulsa de su mundo primigenio, anulando la posibilidad del retorno, es decir que ya no puede reincorporarse a la realidad que perdió por efecto de un abandono que fue producto del arbitrio de su propia voluntad. En consecuencia, el retorno no hará más que confirmarle su condición de extranjero mediante la incapacidad de experimentar como suyas y, por ende, propias, las vivencias que antaño le pertenecieron. 
En Cárdenas, no obstante, el regreso es positivo y alegre; es un retorno físico, pero también mítico a esa ciudad perdida, en que el sujeto espera con optimismo reencontrarse con el paisaje austral, sus amigos y ancestros. El hablante confía en la circularidad y monotonía del tiempo, hallándose, de este modo, frente a uno mítico y a otro que asume el carácter de detenido. Refiriéndose al primero, en el poema "Regreso", señala que éste no es más que regreso a otro tiempo, y aun cuando sabe que muchos de sus amigos y familiares ya no estarán para recibirlo, confía en la presencia del boliche o de la mesa, en la que se sentará a probar el pan de otros días y a conversar, tal vez, con nuevos "comensales, asuntos que nadie olvida". Tiene la convicción de que siempre habrá algo que convoque la presencia de las horasidas: los pájaros, por ejemplo, le servirán para recordar el bosque de pinos, así como la lluvia para pensar en el invierno de la provincia o "para revivir mejor los grandes fríos".

El sujeto lárico teillieriano experimenta el recuerdo en calidad de sobreviviente y guardián de un mundo secreto, rescatando del olvido las tradiciones culturales que en él se conservan. En muchos de sus poemas estesujeto es autor de profundas contradicciones, que pudieran sugerir alienación o desarraigo, sobre todo porque el retorno a su aldea tienela impronta de la extrañeza, esto es, de una sensación de no pertenencia o no reconocimiento con el lugar de origen: él no se reconoce, pero tampoco los demás le reconocen. Se crea de esta forma la imagen del forastero que retorna, como el hijo pródigo a su pueblo natal, a reencontrarse con sus orígenes, pero que asumela búsqueda de ese hallazgo como frustración y, en el peor de los casos, como desilusión y pérdida de todo ideal. La certeza que tiene es queése ya no es su lugar y quelo único que leespera es volver a partir, pues se hace consciente de que una vez abandonado el pueblo éste ya no se recupera. Esta conciencia nada alegre es la que le otorga a los poemas una atmósfera de desesperanza. En "Pequeña confesión", de Para un pueblo fantasma, reflexiona:

Tal vez nunca debí salir del pueblo donde cualquiera puede ser mi amigo donde crecen mis iniciales grabadas en el árbol de la tumba de mi hermana

El sujeto puede activar los gestos cotidianos de la comunidad y el hogar, en tanto testigo u observador de la realidad, mas no como participante de aquélla, es lo que ocurre, por ejemplo, en el poema "Los conjuros", en el que describea la familia celebrando la noche de San Juan:

Los temerosos de los brujos vecinos lanzan puñados de sal al fuego 


\begin{abstract}
cuando pasan las aves agoreras Los buscadores de entierros en sueños hallan monedas de oro Los despierta el jinete del rayo cayendo hecho llamas entre ellos
\end{abstract}

No obstante, el sujeto no se identifica con el rito ni se involucra con el entramado ideológico que lo orienta, pues su presencia evanescente sólo se hace notar para exclamar que ya no reconoce su casa. Finalmente, cuando despierta, se da cuenta de que toda la escena descrita corresponde simplemente a un sueño, del que, sin embargo, conserva las hierbas y la tierra de un lugar fantasmagórico dondenunca estuvo. Dicha vivencia confirma la tesis de quela evocación de los ambientes del lar es posible mientras exista un objeto que reúna su esencia y que sea capaz de ser aprehendido por la memoria del poeta, mas no por su empiricidad, en tanto que el mundo lárico existe únicamente como desintegración, fracaso o ruptura.

En Teillier, la presencia del objeto lárico traduce la nostalgia y abulia del hablante en afecto y arraigo a lo propio, a ese mundo caritativo y comunitario de la provincia; afecto que emplea para evadirse tanto de la angustia existencial cuanto de la indiferencia. Cuando se evocan las manzanas, la sidra o el tílburi de los abuelos, el sujeto confirma su existencia en cuanto corolario de las formas de vida que en ellos están impregnadas. D e este modo, le es posible dejar testimonio de aquel mundo, de la paz y la tranquilidad que situaciones tan sencillas pueden ofrecerle a su vida actual (pero que no bastan para resguardarlo de la desintegración que lo amenaza, simultáneamente, tanto desde el exterior como desde el interior del mismo). Ese mundo verdadero le permite resistir contra aquel otro modernizante, del cual sí se siente voluntariamente desarraigado. Por eso, tempranamente, en los instantes en que percibe la decadencia o extinción del mundo lárico, vale decir, la desaparición de la aldea y sus habitantes, se consuela pensando que:

Es bueno saludar los platos y el mantel puestos sobre la mesa y ver que en el viejo armario conservan su alegría

el licor de guindas que preparó la abuela

y las manzanas puestas a guardar.

Cuando la forma de los árboles

ya no es sino el leve recuerdo de su forma, una mentira inventada por la turbia memoria del otoño

("O toño secreto", Para ángeles y gorriones, 1956). 
La conciencia del paso del tiempo, la soledad y el desarraigo, frente a la invasión de cosas irreales, "que desalojan el mundo natural y van aislando al hombre del seno de su verdadero mundo" (1965: 52), hace que el sujeto, en reiteradas ocasiones, se perciba a sí mismo convertido en extranjero de su pueblo. Esto, sin embargo, no le impide tener confianza e, incluso, la más profunda convicción de que el mundo de la aldea y sus formas de vida son las únicas verdaderas, que, aun en vías de extinción, él puede resguardar mediante el acto memorioso de recordar, porque, en última instancia:

No importa que los días felices sean breves como el viaje de la estrella desprendida del cielo, pues siempre podremos reunir sus recuerdos así como el niño castigado en el patio encuentra guijarros con los cuales formar brillantes ejércitos pues siempre podremos estar en un día que no es ayer ni mañana mirando el cielo nacido tras la lluvia y escuchando a los lejos un leve deslizarse de remos en el agua (Los trenes de la noche y otros poemas, 1961).

El sujeto que regresa a su ciudad natal en el poema "Regreso" de Cárdenas, en cambio, no es un extraño 0 , de mejor forma, no se sienteun extraño, al guien a "quien no esperan". Por el contrario, se siente feliz con la idea de regresar a los mismos lugares y de saber que siempre habrá al go 0 al guien que lo estará esperando. En él está la creencia de que aun cuando el tiempo haya transcurrido, llevándose a muchos de sus seres queridos:
Alguien nos reconocerá a la vuelta de una esquina.
Aún existirá el boliche donde se reunían viejos campesinos. N os invitarán a beber y a conversar asuntos que nadie olvida

En sus poemas, el tiempo, no siendo el del origen, tiene la capacidad de detenerse, de manera tal de capturar los instantes de la vida cotidiana que le brindan al sujeto la confianza suficiente para retornar siempre y con el mismo optimismo a su aldea natal.

En suma, la reconstrucción del medio familiar y de la casa natal se realiza mediante la exaltación de la monotonía de los gestos y situaciones de la vida diaria, donde no hay asombro, novedad o temor; donde se actúa por inercia 0 por la fuerza de la costumbre. N o obstante, esta rutina vienea confirmar otra de 
las preocupaciones fundamentales del poeta lárico: la búsqueda de arraigo en un pasado que no es el dela infancia, entendido como un tiempo mejor, sino el del mito, como un tiempo en el que se repiten los gestos que aseguran la continuidad de las labores cotidianas. Sin embargo, en poemas como "La quinta de la casa" o "La familia reunida" se relata la monotonía de la vida familiar no precisamente como una escena mítica, que desde un tiempo inmemorial y eternamente continuará igual, sino más bien, como la imagen de un tiempo detenido en la memoria del sujeto que, corresponda o no a la del mito, le permite construir de manera optimista un presente sobre las bases de aquellas imágenes de la vida cotidiana, cuya estaticidad lo impregna de sentido y esperanza.

M ientras que en la poesía de Teillier la monotonía revelará a un sujeto nostál gico y, en ocasionesincluso, aburrido de ella, pero que, a fin decuentas, viene a confirmar en poemas como "Bajo el cielo nacido tras la lluvia" u "O toño secreto", que es en ese mundo sencillo, que se repite eternamente un año tras otro, donde está la esencia de la felicidad. Teillier no postula un mundo que haya sido mejor en el pasado, como tampoco uno que pudiera serlo en el futuro. Afirma un presente en el que están contenidos los restos de ese pasado mítico-ancestral, queél identifica en las comunidades y aldeas del sur del país, rescatando del olvido las formas de vida en comunidad que sobreviven a través de las actividades del recuerdo y del testimonio. No obstante, resulta contradictorio que el sujeto asuma una voluntad abatida por el tedio y la costumbre justo en los momentos en que logra integrarse al ciclo eterno del mito, pues aun en esta dimensión el presente es experimentado como esterilidad y abandono, careciendo de sentido e intensidad.

El sujeto poético en los poemas de Cárdenas, por el contrario, resuelve la ambival encia deun habitante extranjero que retorna a su lugar de origen, acompañado siempre de los gestos cotidianos de sus familiares y amigos. Éste logra adoptar de sus antepasados la cultura y la historia que le han legado como ejemplo de vida sincera, bondadosa y "real", pudiendo, de este modo, conciliar el momento del idilio (por ende, del pasado mítico) con el dela realidad imperfecta del presente, vale decir, la del tedio y la apatía que terminan apoderándose del sujeto teillieriano.

\section{A MODO DE CONCLUSION}

La obra poética de Rolando Cárdenas se inserta en la corriente lárica de la poe sía chilena contemporánea que, de acuerdo con Jorge Teillier, designa un cierto tipo de escritura, cuya característica más relevante es la preocupación del poeta por resguardar una cierta realidad secreta, que pervive en las formas de vida 
comunitaria de las provincias y aldeas de lo que el mismo autor ha señalado como la Frontera o nuestro far west chileno. Con "Los poetas de los lares... ", Teillier instaura una línea de estudio para explicar la función del poeta como guardián del mito, en tanto éste, guiado por un fuerte impulso romántico, debía preservar aquellas auténticas formas de vida, impregnadas de las tradiciones y costumbres del mundo cultural al que pertenecen. Son ellas y los objetos que las recuerdan los que le permiten afirmar la vida como un mundo bien hecho, en oposición al mundo alienante de la modernidad, que no se sustentaría en ningún elemento cultural trascendente.

La poesía de Cárdenas se hace parte de las proyecciones poéticas del mundo lárico teillieriano, en tanto asume como actitud básica su lealtad al suelo natal, a la provincia magallánica, lugar de origen del poeta. Su obra está signada por los gélidos ambientes de esta región, siendo la lluvia y la nieve perpetuos referentes de sus textos. Y si la geografía del paisaje austral se hace notar en ellos, no con menosahínco sedestaca su preocupación por el habitante magallánico y sus formas devida. En este sentido, Cárdenas asume plenamente el ideal deTeillier de rescatar la cotidianidad de la vida en provincia como mecanismo de defensa y resistencia contra el mundo moderno. Y si bien en la poesía del autor el sujeto combate inútilmente contra su principal enemigo, el tiempo, tienela certeza de que su hábitat constituye un mundo mítico capaz de trascenderlo. Al igual que en Teillier, este sujeto tiene conciencia de la caducidad de la existencia humana, experimentando el paso del tiempo, tal vez, con mayor angustia, pero el anhelo deretornar a ese mundo idílico al quepertenecen susabuelosy demás ancestros, le otorga la fuerza suficiente para sobrevivir fuera de él, en la ciudad.

Esto hace que su visión de mundo se adapte a las categorías de lo lárico definidas por Teillier en sus reflexiones metatextual es "Los poetas deloslares..." y "Sobre el mundo donde verdaderamente habito", en tanto que el poeta se sitúa en la tierra, describiendo el paisaje magallánico como impregnado de vida y de una fuerza telúrica que le imprime a su habitante la esencia de su mundo. Así, el sujeto jamás se despojará de sus motivos íntimos y vitales (el mar, el viento, la escarcha o la nieve), creando junto a ellos un mundo cultural que le permitirá estar bajo el amparo y compañía de los seres y objetos que más ama; mientras que, a través de la remembranza, le será posible recuperar un espacio secreto y un tiempo ancestral arcádico: la provincia magallánica, el hogar, sus habitantes y formas de vida; experiencia que confirma que el poeta lárico jamás estará solo mientras escuche el pulso de sus antepasados que lo llaman a activar la historia pasada, para que en su vida presente conserve la vitalidad y plenitud de aquélla. 


\section{REFERENCIAS}

Cárdenas, Rolando. 2001. O bra completa. Punta Arenas: Corporación Cultural Sur del Sur, Ilustre M unicipalidad de Punta Arenas.

N ómez, N aín. 1992. Poesía chilena contemporánea. B reveantología crítica. Santiago de Chile: Universitaria.

Teillier, Jorge. 1965. "Los poetas de loslares", en Boletín dela U niversidad deChileN 56: 49-53.

----- . 1968. "Sobreel mundo donde verdaderamente habito", en revista Trilce № 14: 13-17.

----- 1999. Para ángeles y gorriones. Santiago de Chile: U niversitaria.

----- 2004. El cielo cae con lashojas. El árbol de la memoria. Los trenesdela noche. Santiago de Chile: Tajamar.

------- 2004. Para un pueblo fantasma. Val paraíso: Ediciones U niversitarias deValparaíso.

----- . 2005. M uertes y maravillas. Santiago de C hile: U niversitaria. 
